\title{
Development of a mathematical model for the composting process
}

\author{
F. Gironi \& V. Piemonte \\ Department of Chemical Engineering Materials \& Environment, \\ University of Rome "Sapienza", Italy
}

\begin{abstract}
Composting is a powerful process for the treatment of the organic fraction of municipal solid wastes (MSWs), yard and green wastes. The process is performed aerobically by means of specific micro organisms that utilize organic matter for their metabolism producing, as metabolites, water, carbon dioxide and humus (a solid substance that can be utilized for agricultural uses). Composting of organic solid residues has a positive environmental impact because it reduces the volume of solid wastes to be landfilled and, consequently, the production of methane (often characterized by low recovery efficiency) due to the anaerobic degradation of organic solids. Indeed, the release of methane in the environment is very dangerous because the effect of methane as greenhouse gas is about 20 times higher than that of carbon dioxide.

In this paper, a mathematical model of the composting process is presented in order to predict its performance and to contribute to the solution of practical design problems. Energy and mass balance equations, with typical kinetic expressions for degradation of organic matter, provide the basis of the composting model. The process was split into two stages: in the first, the "Running phase", the substrate biodegradation reactions take place, while in the second, the "Loading phase", air and water are supplied to the composting reactor. The effects of the characteristic time of each phase on the BVS, oxygen and water concentrations inside the composting reactor were also studied.
\end{abstract}

Keywords: mathematical model, aerobic composting, simulations. 


\section{Introduction}

Composting is the biological decomposition and stabilization of organic substrates, under conditions that allow the development of high temperatures (thermophilic temperature) as a result of biologically produced heat. The composting process produces a final product that is stable, free of pathogens and plant seeds, and can be beneficially applied to land. Thus, composting is a form of waste stabilization that requires special conditions of moisture and aeration to produce thermophilic temperatures (Haug et al. [1]).

In aerobic composting, air is forced through a high-solids organic matrix to support aerobic metabolic activities. The products of the metabolic activities are water, carbon dioxide, ammonia and heat. Thus, composting is a complex bioprocess that involves many coupled physical and biological mechanisms. These coupled, and often nonlinear, mechanisms yield a broad spectrum of phenomena that have been analysed both empirically and theoretically (Higgins and Walker [2]). Mathematical modelling provides a powerful tool for understanding the dynamical interactions between these coupled mechanisms, and provides a framework for rational process design. In other words, reactor models can serve as an essential tool for faster and better process design, system analysis, and operational guidance (Petric and Selimbasic [3]). Mathematical models of the composting process have appeared in the literature since 1976, with more than 30 papers addressing this topic published through to December 2003 (Mason [4]). In addition, contributions from studies on liquid-phase aerobic digestion, and the broader field of high-solids aerobic degradation, provided models with potential relevance to the understanding and prediction of composting system behaviour (Higgins and Walker [2], Petric and Selimbasic [3], Whang and Meenaghan [5], Nakasaki et al. [6], Das and Keener [7]).

It is commonly accepted that the process variables that affect the composting process are aeration rate, moisture content and reactor temperature (Walker et al. [8]). Generally, the aeration rate required for heat removal is much greater than either stoichiometric or final drying requirements (MacGregor et al. [9], Haug [10]). In addition, cooling by aeration leads to high rates of moisture removal from the organic matrix (Robinson and Stentiford [11], Keener et al. [12]). If severe enough, this moisture loss can result in a significant reduction in the decomposition rate.

In this paper, a mathematical model of the composting process is presented in order to provide a valid tool to predict the process performance and to contribute to the solution of practical design problems. Energy and mass balance equations, with typical kinetic expressions for degradation of organic matter (Higgins and Walker [2]), provide the basis of the composting model.

A batch reactor operating in two different phases (Running phase and Loading phase) was considered. The effects of the reactor running phase time on the oxygen concentration and the moisture content inside the composting were also assessed. 


\section{Mathematical modelling}

The present work deals with the mathematical modelling of composting process split in two stages: in the first one ("Running phase") the substrate biodegradation reactions take place, while in the second one ("Loading phase") air and water are supplied to the composting reactor in order to maintain the oxygen concentration in gas phase and the moisture content in solid phase above a threshold value.

The modelling of running phase has been carried out in the hypothesis that both solid and gas phases are internally well-mixed and biodegradation reactions take place at interface between the solid and gas phases.

The loading phase is assumed to be very short with respect to the running phase (at least one order of magnitude), so the degradation reactions in the organic phase can be neglected, while oxygen and water concentrations inside the reactor owing to the air stream which enters composting unit.

In this study the composting apparatus was represented by a cylindrical wellmixed apparatus: during the running phase the system is closed whereas during the loading phase the system is opened (see in figure 1). The apparatus has a total volume $V$, partly filled with the solid phase $\left(V_{s}\right)$ and partly filled with the gas phase $\left(V_{G}\right)$. The solid phase consists of volatile organic solids (BVS) and is characterized by a bed porosity, $\varepsilon=0.5$; the pores are filled with gas having the same composition of bulk gas phase. This phase consists of nitrogen (inert) oxygen (reactant) and reaction products like water and carbon dioxide.

Through mass and energy balance, process chemistry, transport processes and thermodynamics, a set of equations describing a well-mixed composting process was derived. In particular, BVS content in composting unit vs. time was deduced as a function of temperature, moisture content and oxygen mass fraction. These state variables are the most important for representing the compost process dynamics.

\subsection{Running phase}

Mass balance of BVS can be written as follows

$$
\frac{d(B V S)}{d t}=-k_{s} \frac{C_{O_{2}}}{K_{O_{2}}+C_{O_{2}}}(B V S)
$$

where BVS is the biodegradable volatile dry solid mass loaded inside the composting reactor, $\mathrm{C}_{\mathrm{O}_{2}}$ is the oxygen concentration $(\% \mathrm{v} / \mathrm{v}), K_{\mathrm{O}_{2}}$ is the half velocity constant as defined by Richard et al. [13] and $k_{s}$ is a semi-empiric kinetic parameter defined as

$$
k_{s}=\frac{\beta_{r} R_{C_{2} o p t}}{10^{3} \gamma_{O_{2}}}\left(f_{T}\right)
$$


where $\beta_{r}$ is a respiration quotient $(\mathrm{gO} 2 / \mathrm{gCO} 2), R_{\mathrm{CO} 2 \text { opt }}$ is the optimal $\mathrm{CO} 2$ evolution parameter (g CO2/ $\mathrm{kg}$ volatile solids per day), $\gamma_{\mathrm{O}_{2}}$ is a specific oxygen uptake factor, ( $\mathrm{kg} \mathrm{O} \mathrm{O}_{2}$ consumed/kg BVS oxidized), while $f_{T}$ is an empirical function that accounts for temperature effects on the BVS reaction kinetics. According to Higgins and Walker [2] the following definition of $f_{T}$ has been utilized:

$$
f_{T}=\frac{\left(T-T_{\max }\right)\left(T-T_{\min }\right)^{2}}{\left(T_{o p t}-T_{\min }\right)\left\{\left(T_{o p t}-T_{\min }\right)\left(T-T_{o p t}\right)-\left(T_{o p t}-T_{\max }\right)\left(T_{o p t}+T_{\min }-2 T\right)\right\}}
$$

where $T_{\min }$ and $T_{\max }$ are the minimum and maximum temperatures for system bioactivity, respectively, and $T$ is the composting reactor temperature.

As for the energy balance, it was assumed that BVS oxidation reaction is the main source of energy, therefore the rate of internal energy variation is related to BVS oxidation kinetics through the heat of reaction, $\Delta H_{r}$, which is assumed temperature independent. Therefore, the time rate of temperature change within the reactor is given by

$$
\frac{d T}{d t}=\frac{h A\left(T-T_{a}\right)-\Delta H_{r} \frac{d(B V S)}{d t}}{V_{s}\left(\varepsilon \rho_{a}(T) c_{a}+\rho_{s}\left(c_{s}+M_{s} c_{w}\right)+\varepsilon \rho_{a}(T) U_{s}(T) c_{v}\right)+V_{G} \rho_{a}(T)\left(c_{a}+U_{s}(T) c_{v}\right)}
$$

where $h$ is the heat transfer coefficient for natural convection $\left(\mathrm{kcal} / \mathrm{m}^{2}\right.$ dayK) between the reactor and the ambient system (it was neglected the reactor wall resistance to the heat transfer), $A$ is the external reactor surface, $T_{a}(\mathrm{~K})$ is the ambient temperature, $U_{s}(\mathrm{~T})$ is the saturated humidity at reactor temperature $(\mathrm{kg}$ $\mathrm{H} 2 \mathrm{O} / \mathrm{kg}$ dry air); $\rho_{a}\left(\mathrm{~kg} / \mathrm{m}^{3}\right)$ is the density of dry air at reactor temperature; $c_{a}$, $c_{b}, c_{v}$ and $c_{w}(\mathrm{kcal} / \mathrm{kg} \mathrm{K})$ are the specific heat of dry air, dry solids, liquid water and water vapour, respectively; $\rho_{s}\left(\mathrm{~kg} / \mathrm{m}^{3}\right)$ is the dry bulk density of the solids; $M_{s}$ is the moisture content dry basis ( $\mathrm{kg}$ water $/ \mathrm{kg}$ dry solids). Specific heat and density of constituents were held constant.

The heat transfer coefficient in natural convection, $h$, was calculated by (Bird et al. [14])

$$
h=1.22\left(\frac{T-T_{a}}{D}\right)^{1 / 4}
$$

where $D$ is the reactor diameter.

The oxygen stored within the organic matrix is measured by the oxygen mass fraction within the pore space of the organic matrix. The change of the oxygen mass fraction in the matrix, $X_{O_{2}}$, was model by 


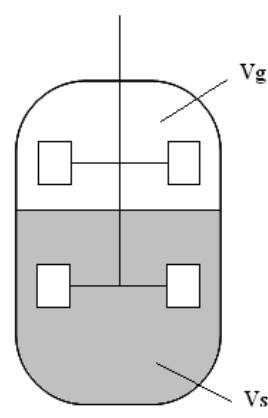

Running phase

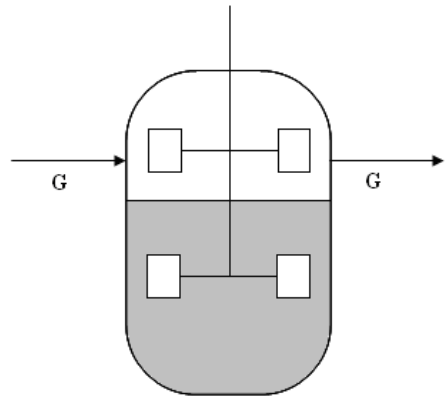

Loading phase

Figure 1: Composting reactor operations scheme.

$$
\frac{d X_{O_{2}}}{d t}=\frac{y_{O_{2} / B V S} \frac{d(B V S)}{d t}}{V_{s} \varepsilon \rho_{a}(T)}
$$

where $y_{O_{2} / B V S}$ is the yield coefficient of $\mathrm{O} 2\left(\mathrm{~kg} \mathrm{O}_{2} / \mathrm{kg} \mathrm{BVS}\right.$ oxidized).

Finally, as for moisture content in the solid phase, it was assumed that water is produced by the BVS oxidation, and its production rate is related to oxidation rate by a constant yield coefficient $y_{H_{2} O / B V S}$ [2]. Therefore, the mass of water in the organic matrix vs. time is given by the following differential equation:

$$
\frac{d M_{s}}{d t}=\frac{y_{H_{2} \mathrm{O} / \mathrm{BVS}} \frac{d(B V S)}{d t}}{V_{s} \rho_{s}}
$$

where $y_{\mathrm{H}_{2} \mathrm{O} / \mathrm{BVS}}$ is the yield coefficient of $\mathrm{H}_{2} \mathrm{O}\left(\mathrm{kg} \mathrm{H}_{2} \mathrm{O} / \mathrm{kg}\right.$ BVS oxidized).

\subsection{Loading phase}

During the loading phase (which is supposed very fast with respect to the running phase) it can written the same material and energy balance equations reported previously. Since the biodegradation reactions were neglected, the mass of BVS do not varies during the loading phase. The air uptake from the ambient system leads to a variation of the oxygen concentration in the gas phase and to a variation of water concentration in the liquid phase, due to a possible moisture condensation from the gas phase. In other words, it was assumed that the only water inflow into the reactor volume was water vapour in the saturated air used for aeration. It was also assumed that there was no resistance to the transport of 
moisture from the organic matrix to the air. Thus, the following balance equation for water in solid phase can be written:

$$
\frac{d M_{s}}{d t}=\frac{G\left(U_{s}\left(T_{a}\right)-U_{s}(T)\right)}{V_{s} \rho_{s}}
$$

where $G$ is the mass flow rate of dry air (kg dry air/day) and $U_{s}\left(T_{\mathrm{a}}\right)$ is the saturated humidity at ambient temperature $\left(\mathrm{kg} \mathrm{H}_{2} \mathrm{O} / \mathrm{kg}\right.$ dry air).

Oxygen inflow was modelled by assuming that oxygen only enters the compost matrix through the forced aeration with ambient air

$$
\frac{d X_{O_{2}}}{d t}=\frac{G\left(X_{O_{2}, a}-X_{O_{2}}\right)}{V_{s} \varepsilon \rho_{a}(T)}
$$

where $X_{O_{2}, a}$ is the concentration of oxygen in ambient air $\left(\mathrm{kg} \mathrm{O}_{2} / \mathrm{kg}\right.$ dry air).

Finally, since there is little or no resistance to heat transfer from the compost matrix to the air in the compost vessel, it was assumed that the temperature of the gas is equal to the temperature of the solid phase [2]

$$
\frac{d T}{d t}=\frac{h A\left(T-T_{a}\right)+G\left(c_{a}+U_{s}\left(T_{a}\right) c_{v}\right)\left(T_{a}-T\right)-\lambda_{w} G\left(U_{s}(T)-U_{s}\left(T_{a}\right)\right)}{V_{s}\left(\varepsilon \rho_{a}(T) c_{a}+\rho_{s}\left(c_{s}+M_{s} c_{w}\right)+\varepsilon \rho_{a}(T) U_{s}(T) c_{v}\right)+V_{G} \rho_{a}(T)\left(c_{a}+U_{s}(T) c_{v}\right)}
$$

where $\lambda_{w}$ is the heat of vaporization of water.

In order to obtain simulated curves, the set of differential Eqs. (1)-(10) was integrated numerically with the gPROMS package (Process System Enterprises, London, UK).

Values of the several parameters used in the composting process model are taken from Higgins and Walker [2] and Richard et al. [13].

\section{Results and discussion}

The simulated curves are obtained considering a reactor volume of 20 litres, an initial content of BVS of $3.3 \mathrm{~kg}$ (with $\rho_{s}=0.3 \mathrm{~kg} /$ litre), an initial moisture content of $0.82 \mathrm{kgH} 20 / \mathrm{kg}$ dry solids and an initial reactor temperature of $45^{\circ} \mathrm{C}$. An air flow rate ranging from 90 to $360 \mathrm{~kg} /$ day (wet basis) was also considered.

The most important results obtained from the simulations are reported in figures 2, 3, 4 and 5. It is worth noting that since the model does not include a microbial growth mechanism, it cannot simulate the lag in temperature and oxygen uptake rate during the process.

In figure 2 two different operating conditions are compared, the first one, named "low frequency", characterized by high running and loading times and the second one, named "high frequency", characterized by lower values of the 

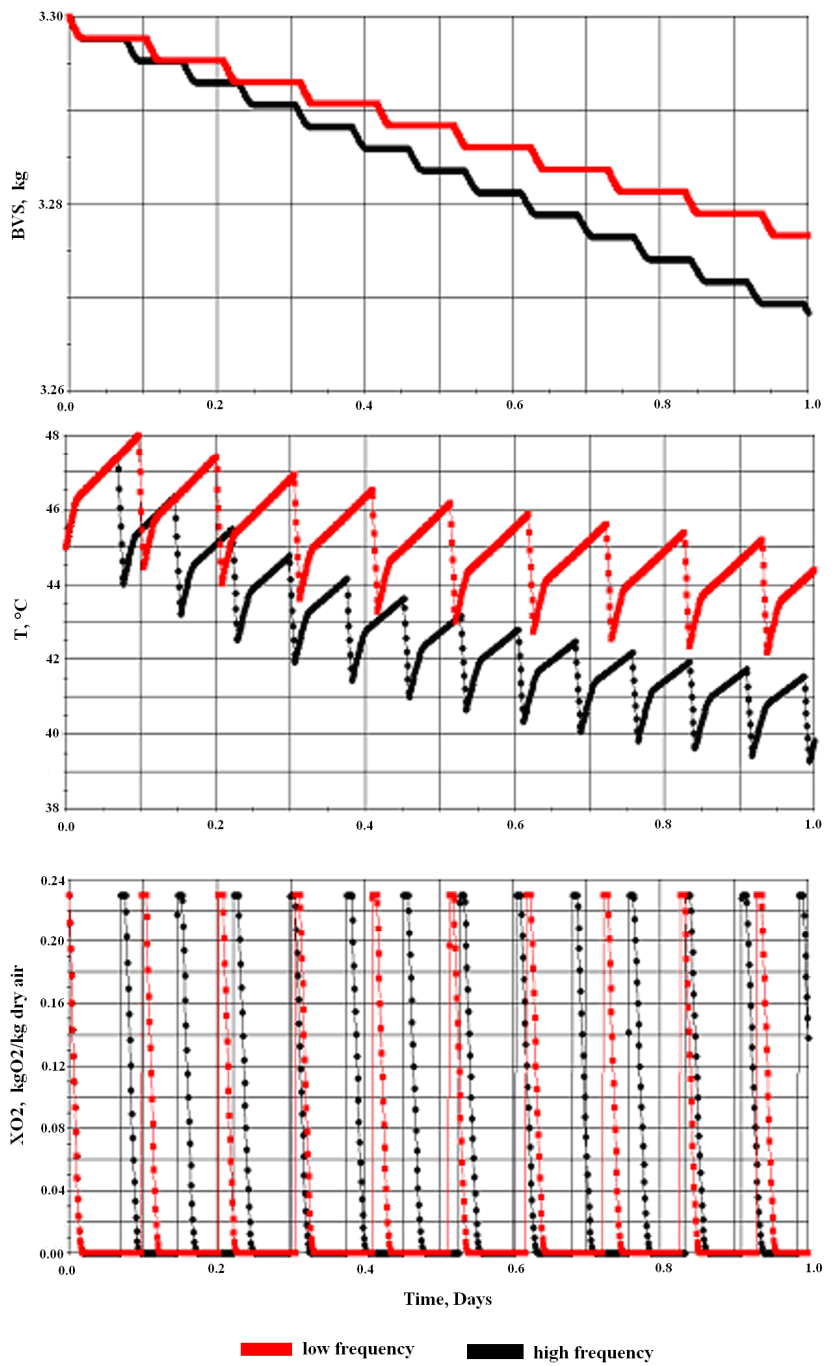

Figure 2: Composting process performance assessed for two different operating conditions; low frequency: running time $=140$ minutes, loading time $=10$ minutes; high frequency: running time $=100$ minutes, loading time $=10$ minutes.

running time. For both the operating conditions it can be observed a decreasing temperature trend (always lower than the thermophilic temperature) that highlights a cooling effect, due to the air uptake during the loading phase, higher than the heating reaction effect of the running phase. 

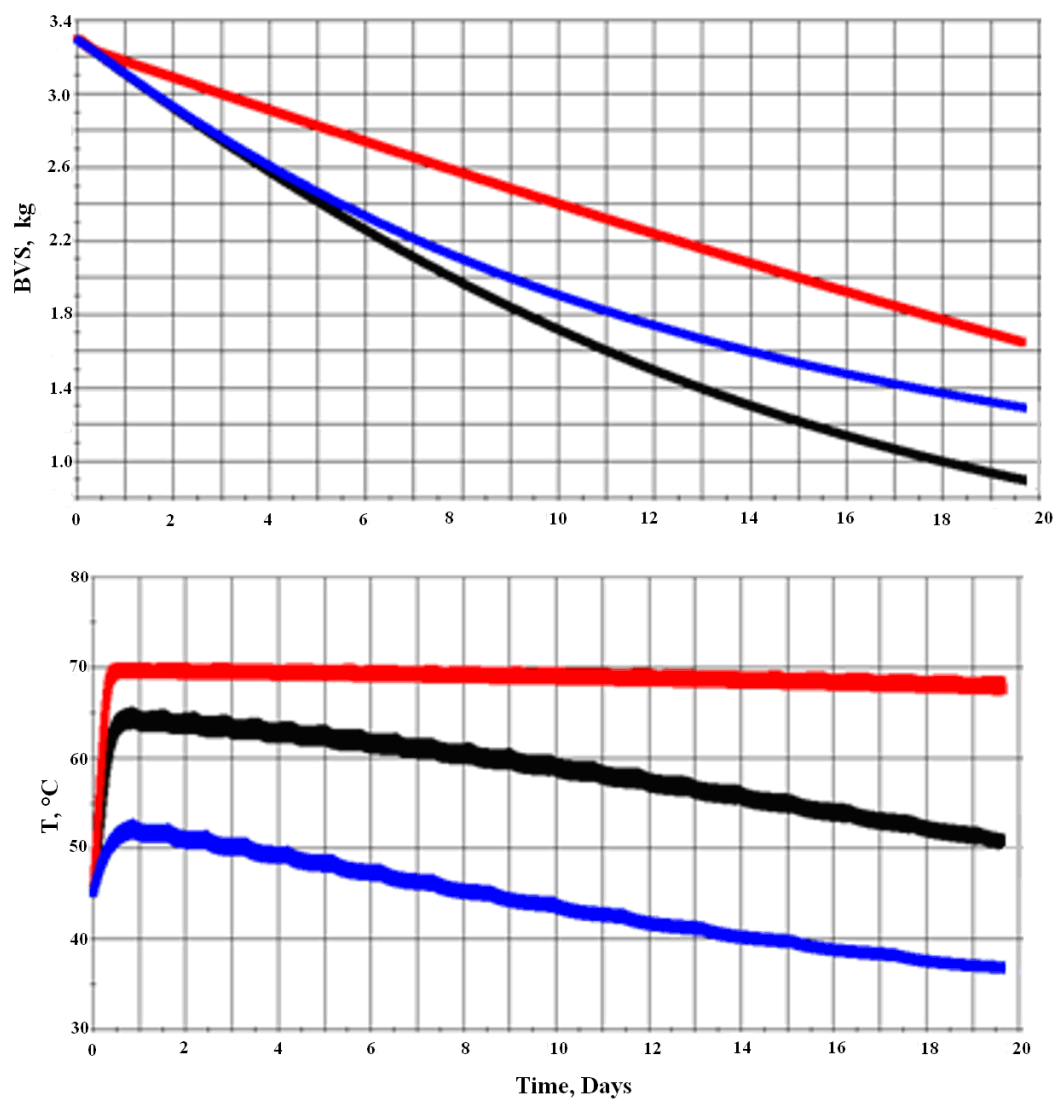

Figure 3: Composting process performance for very high frequency (running time $=14$ minutes, loading time $=1$ minute) at different inlet flow rates with moisture content control.

By analyzing the oxygen concentration inside the reactor, it can be observed a rapid oxygen consumption (as a result of the biodegradation reactions) that reaches an almost zero concentration in times lesser than the running time.

Consequently, when oxygen concentration is approximately equal to zero, the biodegradation reactions do not occur and the BVS mass inside the composting unit is constant (see Figure 2). Furthermore, although the lowfrequency case shows more favourable temperature profiles in terms of kinetic constant rate, the composting reactor works with an oxygen concentration close to zero for a longer time.

Therefore, from an overall point of view, an increase of the frequency of reactor operative cycles (running + loading phase) determines a better reactor behaviour in terms of BVS degradation rate. 
In Figure 3 operative conditions characterized by very high reactor cycles frequency were reported, and air inlet flow rate effect on the reactor performance was assessed. A moisture content control finalized to keep moisture inside the reactor around its optimum value was also considered. Moisture content control is accomplished by spraying liquid water inside the reactor, when water concentration in solid phase $\left(M_{b}\right)$ falls below a threshold value $(0.6 \mathrm{~kg} / \mathrm{kg})$.

Figure 3 shows the trend of the concentration of mass of BVS and temperature versus time for different values of the inlet air flow rate and for loading and running times of 14 and 1 minute, respectively. The figure clearly shows the presence of an optimum inlet flow rate value $(\mathrm{G}=180 \mathrm{~kg} /$ day $)$ : high air inlet flow rate $(2 \mathrm{G})$ determines a severe reactor cooling much below optimal temperature value $\left(58.7^{\circ} \mathrm{C}[2]\right)$ that negatively affects the BVS biodegradation rate. On the other hand, low air inlet flow rate $(0.5 \mathrm{G})$ leads to reactor overheating that strongly reduces the BVS biodegradation rate.

Figure 4 shows the water concentration profile in solid phase. High-frequency $\left(t_{r}=100\right.$ minutes, $t_{l}=10$ minutes $)$ and low frequency $\left(t_{r}=140\right.$ minutes, $t_{l}=10$ minutes) as well as very high frequency cases $\left(t_{r}=14\right.$ minutes, $t_{l}=1$ minute) were analysed. In all the cases an inlet air flow rate equal to $180 \mathrm{~kg}$ /day was considered.

It can be seen that a frequency increase (that is a higher biodegradation rate) determine a more rapid solid matrix drying, therefore it is necessary to increase the frequency of water spray supplied to the composting reactor.

Finally, to maintain the temperature around an optimum value, it can act on the inlet air flow rate used during the loading phase. In fact, in order to avoid an excessive reactor temperature drop (and therefore an excessive decrease of the biodegradation reaction rate) it can decrease the inlet air flow rate to the reactor, while in order to avoid a reactor overheating (due to heat produced by the

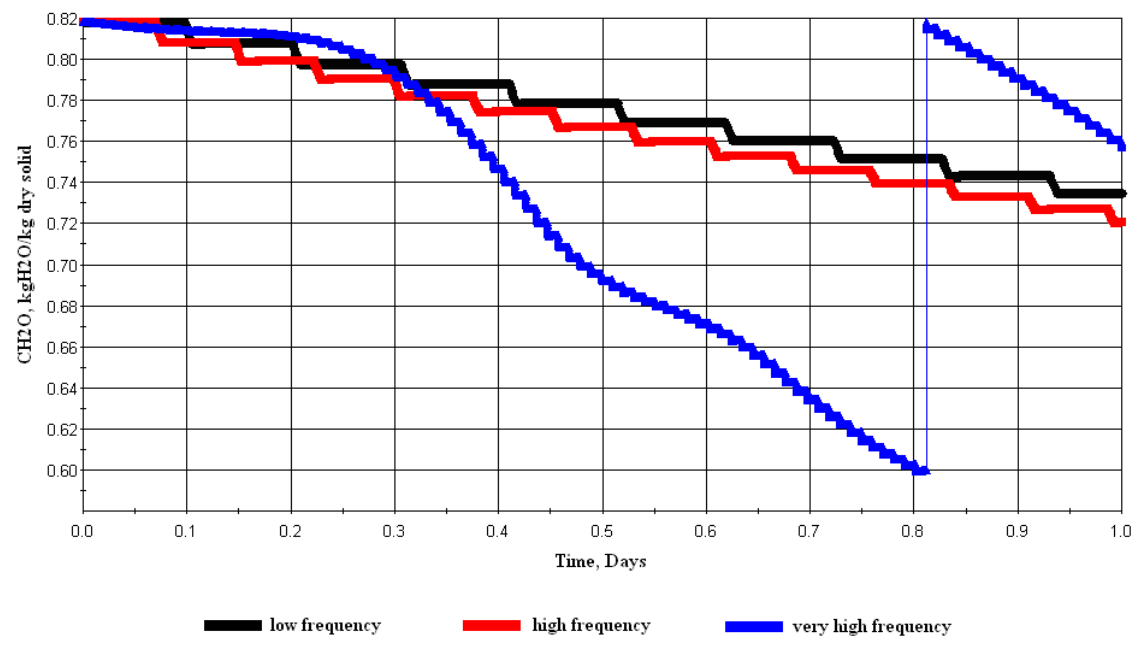

Figure 4: Moisture content profiles for the three operating conditions tested. 

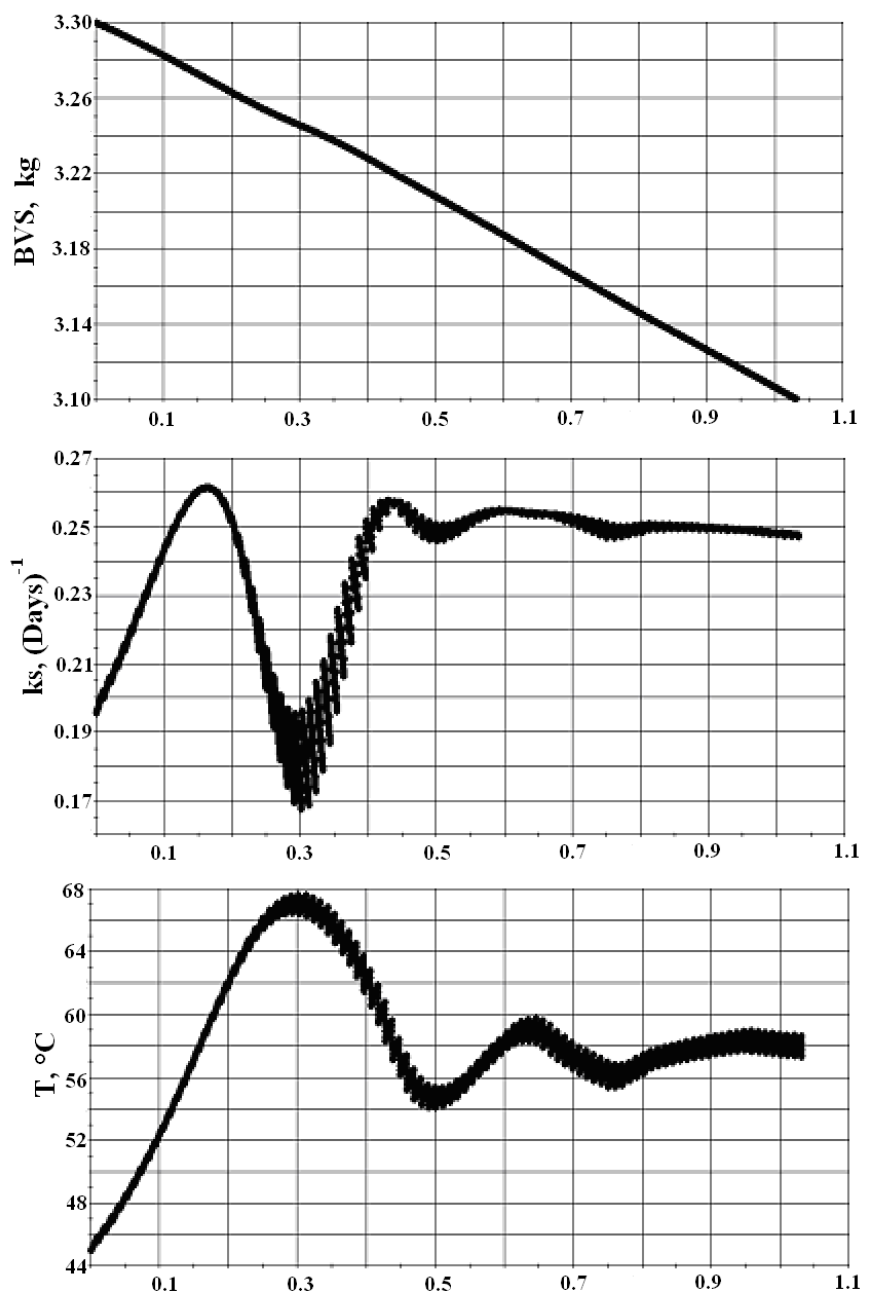

Time, Days

Figure 5: Composting process performance for very high frequency (running time $=14$ minutes, loading time $=1$ minute) with temperature and moisture content control inside the composting reactor.

biodegradation reaction), the same inlet air flow rate can be increased. It was verified that the temperature control is easily achievable by varying of $10-15 \%$ the inlet air flow rate (see Figure 5). It was also verified that this flow rate variation does not alter significantly the oxygen concentration in the gas phase. 


\section{Conclusions}

In this paper, a mathematical model of the composting process was presented in order to predict its performance and to contribute to the solution of practical design problems. The process was split in two stages: in the first one, named "running phase", the substrate biodegradation reactions take place whereas in the second one, "loading phase", air and water are supplied to composting reactor to reach optimal reaction conditions. Several simulations were carried out in order to assess the reactor performance. The results highlighted the importance of the reactor operating times to maximize the BVS degradation rate. Furthermore, by controlling temperature and moisture content inside the composting reactor it is possible to optimize the reactor performance, mainly in terms of biodegradable volatile dry solid removal.

\section{References}

[1] Haug R.T., The Practical Handbook of Compost Engineering, Lewis Publishers, Boca Raton, 385-436, 1993.

[2] Higgins C.W., Walker L.P., Validation of a new model for aerobic organic solids decompositions: simulations with substrate specific kinetics, Process Biochemistry, 36:875-884, 2001.

[3] Petric I., Selimbasic V., Development and validation of mathematical model for aerobic composting process, Chemical Engineering Journal, 139:304-317, 2008.

[4] Mason I.G., Mathematical modelling of the composting process: A review, Waste Management, 26:3-21, 2006.

[5] Whang D.S., Meenaghan G.F., Kinetic model of composting process, Compost Sci./Land Util. 21:44-46, 1980.

[6] Nakasaki K., Kato J., Akiyama T., Kubota H., A new composting model and assessment of optimum operation for effective drying of composting material, J. Ferment. Technol. 65:441-447, 1987.

[7] Das K., Keener H.M., Dynamic simulation model as a tool for managing a large scale composting system, in: Proceedings of Sixth International Conference on Computers in Agriculture, 984-993, 1995.

[8] Walker L.P., Nock T.D., Gossett J.M., VanderGheynst J.S., The role of periodic agitation and water addition in managing moisture limitations during high-solids aerobic decomposition, Process Biochemistry, 34:601612, 1999.

[9] MacGregor S.T., Millier F.C., Psarianos K.M., Finstein M.S., Composting process control based on interaction between microbial heat output and temperature. Appl Eniviron Microbiol, 41:1321-1330, 1981.

[10] Haug R.T., Composting process design criteria: part III-aeration. Biocycle, 27:53-57, 1986.

[11] Robinson J.J., Stentiford E.I., Improving the aerated static pile composting method by incorporation of moisture control. Compost Sci Utilization, 1:52-68, 1993. 
202 Waste Management and the Environment V

[12] Keener H.M., Marugg C., Hansen R.C., Hoitink H.A.J., Optimizing the efficiency of the composting process. In: Hoitink H.A.J., Keener H.M. editors. Science and engineering of composting: design, environmental, microbiological and utilization aspects, Renaissance Publications, Worthington, Ohio, 59-94, 1993.

[13] Richard T.L., Walker L. P., Gossett J. M., Effects of Oxygen on Aerobic Solid-State Biodegradation Kinetics, Biotechnol. Prog., 22, 60-69, 2006.

[14] Bird R.B., Stewart W.E., Lightfoot E.D., Transport Phenomena, Second Edition, John Wiley \& Sons, Inc. 442-443, 2002. 